Expansión urbana

\title{
El borde no es como lo pintan. El caso del borde sur de Bogotá, D. C.
}

\section{The Edge is not How You Paint It. The Case of the Southern Edge of Bogota, D. C.}

A borda não é como todos dizem. O caso da borda sul de Bogotá, D. C.

\section{Leonardo Garavito G.* Amparo De Urbina G. ${ }^{*}$}

Recibido: 14 de diciembre de 2017

Aprobado: 24 de abril de 2018

Doi: http://dx.doi.org/10.12804/revistas.urosario.edu.co/territorios/a.6350

Para citar este artículo:

Garavito, L., \& De Urbina, A. (2019). El borde no es como lo pintan. El caso del borde sur de Bogotá, D. C. Territorios(40), 145-170. Doi: http://dx.doi.org/10.12804/revistas.urosario.edu.co/territorios/a.6350

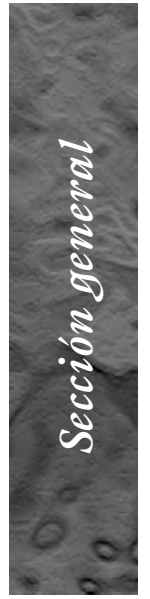

* Ph.D., Estudios Urbanos y Ambientales, Colegio de México A. C. Magister, Estudios de Población y Profesional en Gobierno y Relaciones Internacionales, Universidad Externado de Colombia. Docente e Investigador, Universidad Externado de Colombia. Investigador, Grupo Procesos Sociales Territorios y $\mathrm{Me}$ dio Ambiente, adscrito al Centro de Investigaciones de sobre Dinámica Social (CIDS), Facultad de Ciencias Sociales y Humanas. Correo electrónico: leonardo.garavito@uexternado. edu.co / leo.gara@gmail. com. ORCID: http://orcid. org/0000-0002-5670-5347

** Arquitecta, Pontificia Universidad Javeriana. Magister, Planificación Urbana de la Universidad de los Andes CIDER. Docente, 
Palabras clave

Territorio, expansión urbana, acción colectiva, agua, borde sur de Bogotá

D.C.

Keywords

Territory, urban expansion, collective action, water, south edge of Bogotá D. C.

Palavras-chave

Território, expansão urbana, ação coletiva, água, borda sul de Bogotá D.C.

territarias 40

\section{RESUMEN}

Este artículo presenta reflexiones y avances derivados del proyecto de investigación en curso denominado "Territorios del agua y redes de práctica y aprendizaje para la apropiación del conocimiento y la gestión colaborativa en el borde sur del Distrito Capital". Se enfoca en problematizar y evidenciar la polisemia subyacente tras la idea del borde aplicado a la ciudad y en especial al sur de Bogotá. En este sentido se plantea que hay muchos y diversos bordes interactuando y superpuestos entre sí, apuntando hacia la construcción de una visión más compleja y comprensiva de este territorio. Su metodología se fundamenta en la revisión de fuentes secundarias, complementadas con entrevistas a informantes clave.

\section{ABSTRACT}

This paper presents some reflections and advances derived from an ongoing research project called "Territories of water and networks of practice and learning for the appropriation of knowledge and collaborative management in the southern edge of the Capital District". It focuses on problematizing and evidencing the underlying polysemy after the idea of the border applied to the city of Bogota, and especially to its southern territories. In this sense, it is argued that there are many and different edges interacting and overlapping each other, aiming at building a more complex and comprehensive view of the territory on the southern edge of the Capital District. The methodology is based on the revision of secondary sources, complemented with interviews with key informants.

\section{RESUMO}

Este artigo apresenta reflexões e avanços derivados do projeto de pesquisa em curso denominado "Territórios da água e redes de prática e aprendizagem para a apropriação do conhecimento e a gestão colaborativa na borda sul do Distrito Capital". Foca-se em problematizar e evidenciar a polissemia subjacente por trás da ideia da borda aplicada à cidade e especialmente ao sul de Bogotá. Neste sentido se apresenta que há muitas e diversas bordas interatuando e superpostos entre si, apontando à construção de uma visão mais complexa e compreensiva deste território. A sua metodologia fundamenta-se na revisão de fontes secundárias, complementadas com entrevistas a informantes chave. 


\section{Introducción}

Este artículo presenta reflexiones y avances derivados de la investigación denominada: Territorios del agua y redes de práctica y aprendizaje para la apropiación del conocimiento y la gestión colaborativa en el borde sur del Distrito Capital ${ }^{1}$. Su objetivo general es analizar y fortalecer las prácticas sociales en torno al uso y manejo del agua en el borde sur del Distrito Capital por parte de los acueductos comunitarios, así como las interacciones con los distintos actores de la gestión del territorio, con el fin de construir alternativas para la gestión colaborativa del agua.

En particular, este texto problematiza e ilustra la complejidad de la idea del borde aplicado a Bogotá y en especial al sur de la ciudad. Desde un punto de vista político administrativo, este territorio se relaciona con las localidades de Bosa, Ciudad Bolívar, Usme y Sumapaz. No obstante, a medida que se observa desde otras ópticas, este borde comienza a perder nitidez, se torna difuso y poroso, se amplía, se contrae $\mathrm{y}$, finalmente, deja de ser uno para convertirse en muchos y diversos bordes.

En este sentido, se encuentra que hay diferentes bordes superpuestos e interactuando entre sí. Sin pretender agotar las posibilidades de pensar la ciudad en relación con su borde, las dimensiones analizadas a lo largo de este texto abarcan diversas miradas desde lo histórico, lo ecológicoambiental y lo sociopolítico. En efecto, en primer lugar, se introduce la evolución del borde político-administrativo de Bogotá durante el siglo $\mathrm{xx}$, con el fin de ilustrar el proceso de definición de su perímetro urbano. Segundo, desde una perspectiva contemporánea, se aborda el borde del impacto ambiental, es decir, el alcance reciente de la huella ecológica de la ciudad: el área de tierra, agua e incluso el aire, necesarios para sostenerla y asimilar sus residuos; este borde es discontinuo y dinámico, varía con la demanda de recursos y puede expandirse incluso más allá de los límites nacionales. Tercero, se retoma la mirada histórica para introducir el borde producto de la urbanización efectiva, de la construcción legal o ilegal de zonas residenciales, comerciales e industriales; este se deriva de la expansión urbana concreta, de la transformación e incorporación progresiva, abrupta, planificada o espontanea de territorios rurales o de conservación natural a la mancha urbana de la ciudad. Cuarto y último, el borde de los conflictos y las luchas sociales, políticas y culturales del sur, lleno de acción colectiva y movilización social crítica y propositiva frente al gobierno de la ciudad. Por ejemplo, esta movilización denuncia y enfrenta los efectos negativos de la expansión urbana al sur por medio de diversas iniciativas, como la defensa de ecosistemas estratégicos para el cuidado del agua (páramos y humedales), la oposición a la minería, la protección de la cultural y los modos de vida campesinos, la valoración de la herencia indígena ancestral, el demanda de condiciones de vida digna, y la denuncia de impactantes injusticias socio-ambientales como la del relleno sanitario de Doña Juana, entre otros.
Universidad Externado de Colombia, Facultad de Ciencias Sociales y Humanas. Investigadora Asociada del Grupo Procesos sociales, territorios y medio ambiente adscrito al Centro de Investigaciones sobre D $i$ námica Social (CIDS). Candidata a Ph.D. en Estudios Sociales de la Universidad Externado de Colombia. Correo electrónico: amparo.deurbina@uexternado. edu.co ORCID: bttp://orcid. org/0000-0002-4939-8297

${ }^{1}$ Este proyecto es financiado por Colciencias y ejecutado por un equipo de las universidades Externado y Javeriana, la Empresa de Acueducto y Alcantarillado de Bogotá (EAAB), y dos organizaciones sociales: Agrópolis Constelar Campesina y la Red Territorial de Acueductos Comunitarios. Por lo tanto, antes que nada, es fundamental agradecer el apoyo de todo el equipo de trabajo bajo la dirección de la dra. Dolly Palacio, ya que gran parte de los contenidos presentados a continuación derivan de debates y disertaciones colectivas. Un agradecimiento especial a Phillipe Chenut por el diseño de la figura 2, sobre la huella ecológica de la ciudad.

territarias 40 147 
Al final del texto se concluye vinculando estas diversas visiones del borde, para proponer la pertinencia de una comprensión más compleja del sur del Distrito Capital. En un sentido amplio, el caso de Bogotá es interesante e ilustrativo para otras ciudades de América Latina, dado que, a pesar de los retos particulares de la gestión territorial de los bordes urbanos, estos guardan cierto grado de identidad y no difieren tan radicalmente (generación de cinturones de pobreza y miseria en áreas periféricas, expansión urbana espontánea y al margen de la ley, destrucción de zonas conservación natural o conflictos sociales, ambientales y culturales con poblaciones locales, entre otros).

\section{Aspectos teórico-conceptuales}

El concepto de 'territorio' funciona como el eje articulador de este texto. De acuerdo con Magnaghi (2011), el surgimiento de las metrópolis es uno de los hitos contemporáneos que caracteriza gran parte de los territorios humanos. En el origen de las metrópolis se encuentra la idea de que la urbanización y la industrialización son las claves modernas para la emancipación de las jerarquías premodernas del poder (los esclavos, siervos, campesinos, colonos). Sin embargo, la evidencia empírica señala que las metrópolis no han consolidado dicha transformación emancipadora y que incluso pueden generar efectos adversos. Según el autor, las metrópolis modernas no pudieron disolver los vínculos sociales con el territorio y la naturaleza y, en contraste, propone que la emancipación planteada se vincula de forma íntima con el regreso al lugar. En este sentido, resalta la importancia de la escala local, contrapuesta con un enfoque que abarque la generalidad de las metrópolis. A partir de lo anterior, se asume que el territorio supone un vínculo indisoluble entre la cultura y la naturaleza, en el que el espacio geográfico es apropiado en la práctica social local, y su forma está determinada por las maneras en que los diferentes grupos humanos ocupan los lugares a lo largo de la historia y producen formas de pensarlo, hacerlo y valorarlo en escenarios de relaciones de poder (Escobar, 2005).

Teniendo en cuenta lo anterior, es fundamental resaltar el papel de agua para la ciudad de Bogotá y sus bordes, como una particularidad territorial transversal que emerge en los análisis a continuación. Por una parte, la abundancia de fuentes de agua influencia su lugar de fundación, pero su proceso de expansión urbana parece negar su presencia, secando la sabana. Por otra parte, si bien, el perímetro urbano de la ciudad en 2015 cuenta con una cobertura de agua potable de 99,97\% (Observatorio Ambiental de Bogotá, 2017) a cargo de la EAAB, el abastecimiento de agua en los territorios de borde dependen en gran medida de los acueductos comunitarios (35 aproximadamente), los cuales participan en procesos sociales que trascienden la prestación de un servicio público, pues se vinculan con la organización de sus territorios, con la defensa de los ecosistemas asociados con el agua (paramos,

Leonardo Garavito G., Amparo De Urbina G. 
bosques y humedales), con la pervivencia de las culturas campesinas y con el esfuerzo quijotesco de contener de la expansión urbana. De múltiples maneras, el agua emerge como un elemento transversal y trascendental en los diversos bordes planteados para el sur de Bogotá.

De forma adicional, cabe aclarar que cada uno de los bordes analizados presenta sus propios rasgos conceptuales y metodológicos. Entonces, para ahorrar espacio y ganar coherencia, se incluyen en el desarrollo de cada sección.

\section{Los bordes político- administrativos}

Más que presentar el perímetro urbano vigente de la ciudad, es interesante observar cómo este se ha transformado para llegar a su estado actual (ver figura 1). En efecto, tras comparar el territorio urbanizado con la delimitación establecida por la normatividad, se evidencia que este la rebasa constantemente como consecuencia del desarrollo de asentamientos informales o ilegales. Esta dinámica genera retos y cuestionamientos constantes sobre la definición y la gestión de los límites oficiales de la ciudad. A continuación, se aborda de forma cronológica, los perímetros urbanos legales establecidos a lo largo del siglo $\mathrm{xx}$ y de las normas que más que influyeron en su crecimiento y desarrollo.

La entrada al siglo Xx (entre 1860 y 1910 ) es una etapa de transición donde se deja de planificar la ciudad existente hasta entonces, para comenzar con la ciudad por urbanizar. Los desarrollos fuera de los territorios urbanizados se permiten siempre

Figura 1. Evolución del perímetro urbano oficial de Bogotá durante el siglo Xx

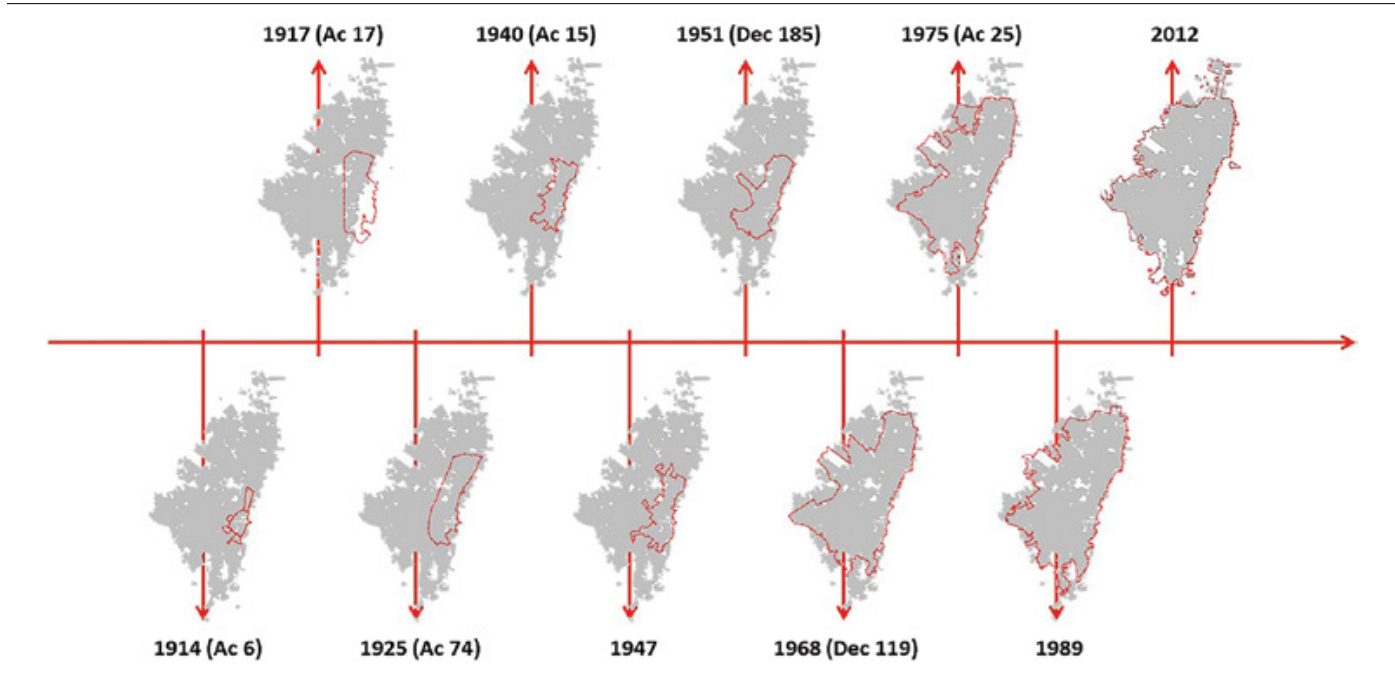

Fuente: elaboración propia con base en diversas fuentes cartográficas. ${ }^{2}$

El borde no es como lo pintan. El caso del borde sur de Bogotá, D. C.

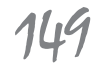

${ }^{2}$ Perimetros 1910-1930 con base en Martínez (2007), Direcciones Municipal y Departamental de Obras Públicas (1925) y Museo de Desarrollo Urbano (1998). Perimetros 1930-1950. Área urbanizada década 1950 con base en Martinez (2007), Secretaría de Obras Públicas Municipales (1940), Secreataría de Obras Públicas. Departamento de Urbanizaciones y Demarcaciones (1938), Ministerio de Hacienda y Crédito Público. Instituto Geográfico Agustin Codazzi, (1946), Oficina del Plan Regulador de Bogotá (1951). Perimetros 1950-1970 con base en Martínez (2007), Oficina del Plan Regulador de Bogotá (1951), Rincón (2010), Castilblanco (2015). Perimetros 19701980. Área urbanizada década 1980 con base en Rincón (2010), Castilblanco (2015), Instituto de Crédito Territorial. Departamento de Estudios e Investigaciones (1975) y Martinez (2007). Perimetros 1980-1990. Área urbanizada década 1990 con base en Rincón (2010), Castilblanco (2015) y Martínez (2007) y Alcaldia Mayor de Bogotá. Departamento Admministrativo de Catastro Distrital.

$$
\Longrightarrow
$$

\section{territorios 40}


Unidad de Cartografía (1989). Perimetros 19902000. Área urbanizada década 2000 con base en Rincón (2010), Castilblanco (2015) y Martínez (2007) y Alcaldía Mayor de Bogotá. Departamento Admministrativo de Catastro Distrital. Unidad de Cartografía (1989).

\section{territarias 40}

y cuando el urbanizador solicite permiso y se comprometa a realizar las obras de urbanismo. En este periodo se pasa de los distritos parroquiales a las secciones de policía, vinculado con la necesidad de un mayor control policial ante el incremento de población (Martinez, 2007).

Entre 1910 y 1930 la población urbana se duplica y se establece un límite urbano mediante el Acuerdo 6 de 1914, que aumenta seis veces el área urbanizada. No obstante, dicha explosión demográfica estimula la instauración de procesos de planificación influenciados por corrientes internacionales. Al final de la década de 1920, se crea el departamento de urbanismo de Bogotá, con el objetivo de generar un reordenamiento de la ciudad que debía resumirse en un plan regulador y un código de urbanismo (Martínez, 2007). En esta etapa, las normas se limitan a darle homogeneidad estética a la ciudad y a garantizar unas condiciones higiénicas básicas, con obras de saneamiento, prestación de servicios públicos, etc. De forma adicional, se reconoce la necesidad de darle un límite máximo de crecimiento urbano a la ciudad, fuera del cual no pueden hacerse nuevas edificaciones ni extenderse las redes de servicio público (Mantilla, 1974). Los principales Decretos y Acuerdos para definir la urbanización son el Acuerdo 6 de 1914, el Acuerdo 17 de 1917 y el Acuerdo 74 de 1925 .

1950 y 1960 son dos décadas de crecimiento demográfico y expansión urbana aceleradas, la población aumenta en más de 2 millones de habitantes y las hectáreas ur- banas en más de 25000. Desde la década de 1940, la urbanización de Bogotá impone una presión muy fuerte para creación del Distrito Especial y anexar varios municipios vecinos, que están soportando la presión de la urbanización con muy pocos recursos. En consecuencia, la Ordenanza Departamental 7 de 1954 incorpora seis municipios a Bogotá: Bosa, Engativá, Fontibón, Suba, Usme y Usaquén. De forma seguida, el Decreto 3640 de este crea el Distrito Especial de Bogotá, que rige oficialmente desde el 1 de enero de 1955. También se crean la Caja de la Vivienda y los fondos para invertir en barrios obreros. A partir de los anteriores elementos, el gobierno de la ciudad comienza a ejercer un control limitado pero creciente sobre su desarrollo urbano. Al respecto, se sugiere ver los Decretos 185 de 1951 y 1119 de 1968.

La década de 1970, el constante proceso de urbanización, se caracteriza por la producción de vivienda legal para todos los estratos, así como la consolidación de barrios de origen informal en las localidades de Santa Fe, Puente Aranda, Tunjuelito y Chapinero; en las localidades de Usme, Kennedy, Bosa, Suba y Ciudad Bolívar se empiezan a dar procesos de urbanización informal. Para este momento, los modelos de planeación se centraron en establecer un patrón de crecimiento y criterios de movilidad urbana, concentrándose en infraestructura vial y de transporte público; trataron temas de crecimiento físico-económico, formas de promoción y ejecución de proyectos de vivienda popular, todo esto planteado en los denominados estudios

Leonardo Garavito G., Amparo De Urbina G. 
Fase I y Fase II que no fueron adoptados por ningún acto administrativo (Martínez, 2007); en esa década solo se formularon dos planes de ordenamiento: el Decreto 1119 de 1968 donde se adoptó el plano general de zonificación de la ciudad (basado en los principios de Le Corbusier, Wiener y Sert) y el Acuerdo 7 de 1979 o Plan General de Desarrollo Integrado, que desarrolla el tema de los desarrollos de vivienda popular localizados fuera del perímetro así como la manera de legalizarlos e incorporarlos a la ciudad (Martinez, 2007).

Entre 1980 y 1990 la ciudad se rige por el Acuerdo 7 de 1979, criticada por implementar un ordenamiento urbano que beneficiaba al mercado inmobiliario, y que prospera gracias a la Unidad de Poder Adquisitivo Constante (UPAC), un sistema financiero de vivienda que se diseñó con la intención de fomentar el sector de la construcción para incentivar la compra de vivienda nueva, la cual era financiada con los excedentes de ahorro de la economía sin que se generaran desequilibrios; mediante el mecanismo de convertir el arriendo en cuotas de amortización que, al aumentar, no alteraran el ritmo de los salarios e ingresos corrientes de las familias (Pizano de Narvaez, 2005). En este escenario creado por la aparición de la UPAC, se desarrolló otra fase de la arquitectura moderna y de los procesos de urbanización y crecimiento de la ciudad, caracterizada por los grandes desarrollos de vivienda en serie, los grandes centros comerciales y los edificios y centros empresariales (Saldarriaga, 2000).
Una de las primeras estrategias adoptadas por las empresas urbanizadoras fue la de la adquisición de grandes porciones de tierra urbanizable, es así como a finales de los años sesenta, buena parte de las tierras periféricas eran propiedad de cuatro empresas constructoras: Ospínas y CIA, Mazuera \& CIA, Pedro Gómez \& CIA y Luís Carlos Sarmiento Angulo \& CIA. Al final de este periodo, se expide la primera Ley de Reforma Urbana (Ley 9 de 1989), muy importante, puesto que es la primera vez que el Congreso se pronuncia frente al ordenamiento urbano del país, un momento en el que se multiplican los procesos de urbanización ilegal, lo cual puede asociarse con una falta de integración entre las políticas nacionales y distritales para la oferta de vivienda de interés social (Pizano de Narvaez, 2005).

A partir de 1990, y hasta 2000, en el marco de una nueva Constitución Politica para Colombia, que le otorga a la propiedad privada una función social, donde el interés general prima sobre el particular, la ciudad continúa urbanizándose y agotando las áreas urbanas disponibles para su desarrollo. Durante este periodo, la norma principal es el Estatuto para el Ordenamiento Físico del Distrito Especial de Bogotá (derivado de la Ley 9 de 1989 y el Acuerdo Distrital 6 de 1990), a partir del cual se definen las Políticas de Desarrollo Urbano y las reglamentaciones urbanísticas para orientar el cambio y crecimiento físico de la ciudad, declarando, entre otras medidas, suelos de expansión urbana. Al final de la década el Estatuto es modificado por la territarias 40

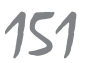


Ley 388 de 1997, obliga a la elaboración de todos los estudios y los documentos técnicos de soporte para el primer Plan de Ordenamiento Urbano de Bogotá; los Planes de Ordenamiento Territorial a nivel nacional se deben estructurar por medio de tres componentes: el general, que se refiere al lago plazo para las áreas municipales; el rural que se refiere al corto y mediano plazo para las áreas rurales; y finalmente el urbano, que se refiere al corto y mediano plazo del proceso de crecimiento urbano, donde es muy importante el criterio adoptado por cada ciudad para definir el Perímetro Urbano, el cual nunca podrá ser mayor que el perímetro de servicios públicos. A lo largo de esta década, los procesos de legalización se consolidan, además que se fortalecen los controles y sanciones en contra de la urbanización ilegal, la cual es declarada delito penal.

En suma, la transformación y la expansión del perímetro urbano durante el siglo XX se enmarca en varios procesos relevantes en su desarrollo: primero, la población aumenta de cerca de $100 \mathrm{mil}$ habitantes a más de seis millones, y su perímetro se expande desde un poco más de 300 hectáreas, hasta casi 178 mil. Segundo, a partir de la segunda mitad del siglo es evidente un interés creciente de las autoridades para gobernar y ordenar este territorio por medio de un proceso de regulación e institucionalización progresiva de la planificación urbana. Tercero, dicha intensión y política gubernamental no es suficiente para controlar el ímpetu de los desarrollos urbanos al margen de la ley, que tienden a superar los perímetros legales de forma sistemática. Ante esto, es posible afirmar que la expansión urbana y la delimitación de su perímetro político administrativo son retos vigentes para la ciudad ad portas del siglo XXI.

\section{El borde de la huella ecológica de Bogotá}

Esta sección amplía readicalmente la idea de los bordes de la ciudad, presentando cómo, por medio de sus patrones de consumo, el impacto de Bogotá se extiende sobre el territorio nacional mucho más allá de su perímetro oficial. En efecto, se presenta un balance de la huella ecológica de la ciudad a partir de una revisión de fuentes secundarias que incluye estudios posteriores al año 2000. La huella ecológica es un indicador de la superficie necesaria para satisfacer los consumos asociados con la alimentación, los productos forestales, el gasto energético y la ocupación del suelo (Wackernagel, et al., 1997) de un grupo social específico. Dicha superfice se expresa en hectáreas por habitante. En efecto, por medio de este indicador se genera a una imagen aproximada de la extención territorial de la demanda de recursos naturales por parte de Bogotá.

A manera de contexto general, según el Global Footprint Network (2017), la humanidad demanda anualmente de forma reciente el equivalente a 1,6 planetas para adquirir sus recursos y absorber sus desperdicios. Esto indica claramente que en la escala global el planeta enfrenta un

Leonardo Garavito G., Amparo De Urbina G. 
importante déficit para su sostenibilidad. Asimismo, refleja que en el presente los niveles de consumo superan ampliamente la oferta de recursos por parte de la naturaleza.

Para el caso colombiano (Global Footprint Network, 2017), en 2012 la huella ecológica per capita fue de 1,9 hectáreas globales. Una hectárea global corresponde a una hectárea biológicamente productiva de acuerdo con el promedio de productividad biológica global de un año dado. Por otra parte, la capacidad biológica per capita del país, es decir, la capacidad del ecosistema para regenerar lo que demanda la gente, es de 3,5 hectáreas globales. Por lo tanto, la biocapacidad menos la huella ecológica señalan un saldo positivo aproximado de 1,7 hectáreas globales per capita en el país.

En comparación con otras naciones, para 2012, la huella ecológica per capita de Colombia se ubica en el puesto 92 entre 150 países, donde los primeros puestos son ocupados por las poblaciones que más recursos demandan. Este listado es liderado por Luxemburgo, Australia y Estados Unidos con huellas ecológicas de 15,8, 9,3 y 8,2 hectáreas globales per capita. En contraste, de acuerdo con la clasificación de países según su huella ecológica total, que corresponde a la huella per capita por el total de habitantes, Colombia ocupa la posición 33 (entre 150). Este listado se encuentra encabezado por China, Estados Unidos, India y la Federación Rusa, seguidos por Brasil, primer país Suramericano en esta clasificación.
De acuerdo con lo anterior, Colombia se encuentra en una situación intermedia a nivel global, donde la riqueza de sus recursos naturales aún es suficiente para cubrir las demandas de su población, incluso con un leve superávit. Sin embargo, la biocapacidad de su territorio revela una clara tendencia decreciente desde principios de la década de 1960, vinculada tanto a al crecimiento poblacional (de 16,5 a 47 millones de habitantes entre 1961 a 2012) como al aumento de la capacidad de consumo de su población medida por los ingresos per capita (de 1400 a 4300 dólares anuales aproximadamente, para el mismo periodo).

Actualmente no hay información estandarizada sobre la huella ecológica para las ciudades a escala mundial; sin embargo, en el caso de Bogotá se identificaron tres estudios posteriores al año 2000 (León, 2013; Contraloría de Bogotá D.C., 2003 \& Parrado, 2001). Para brindar una mayor comparabilidad a sus resultados, se utiliza información poblacional oficial y actualizada según el Departamento Administrativo Nacional de Estadística (DANE) (2017), así como el mismo criterio para el área total del Distrito Capital $\left(1776 \mathrm{~km}^{2}\right)$ y el territorio continental del país ( 1141748 $\mathrm{km}^{2}$ ). En consecuencia, si bien, se parte de los indicadores de huella ecológica per capita de cada estudio, otros indicadores derivados como el tamaño total de la huella ecológica de la ciudad y su proporción en comparación con el área continental nacional pueden variar levemente en relación con los expuestos en las publicaciones territarias 40

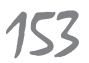


originales. En la figura 2, más adelante, se presentan las diversas estimaciones identificadas para la huella ecológica de Bogotá. Según estas, la huella ecológica total de la ciudad abarcaría por lo menos un área equivalente al departamento de Cundinamarca junto con algunas porciones adicionales de otros departamentos colindantes (Meta, Boyacá, Tolima, Huila y Caldas). Vale la pena aclarar que dichas representaciones son abstractas y solo buscan dar una referencia visual aproximada. Es decir, brinda una imagen aproximada del tamaño de la huella ecológica de la ciudad, sin indicar literalmente los territorios específicos o particulares que esta abarca.

De la más grande a la menor, en primer lugar, de acuerdo con Parrado (2001) la huella ecológica de Bogotá para el año 2000 es de 3,01 hectáreas por habitante. Su cálculo se apoya en una matriz de consumo de usos de la tierra por ciudadano, la cual tiene en cuenta el uso de recursos como energía fósil, áreas edificadas, tierra cultivable, pasto, bosque y mar; en relación con la producción de alimentos, materiales para el hogar y muebles, transporte y bienes diversos.

Según información oficial del DANE (2017), la población de Bogotá en el 2000 fueron 6302881 personas. Por lo tanto, a partir de la huella per capita estimada por Parrado, la huella total del Distrito Capital ascendía a 18971671 hectáreas, equivalentes a $189717 \mathrm{~km}^{2}$. En comparación con el área de la ciudad y del país, corresponde aproximadamente a 107 veces el tamaño del Distrito Capital y abarcaría
$16,6 \%$ del territorio nacional. En la figura 2 corresponde al área sombreada en rojo.

En segundo lugar, el informe ambiental de la Contraloría de Bogotá D.C. (2003) estima un indicador de 2,85 hectáreas de huella ecológica per capita para 2002. Esta medición se basa en las demandas ambientales relacionadas con la movilidad y transporte urbano, el espacio construido, los usos y consumo de agua, los alimentos, la gestión de residuos sólidos y líquidos y la producción y uso de energía.

La población total de Bogotá en 2002 eran 6520473 (DANE 2017) de habitantes, por lo tanto, según la Contraloría, la huella ecológica de la ciudad alcanzaría 18583448 hectareas, equivalentes a $185833 \mathrm{~km}^{2}$. En comparación con el área de la ciudad y del país, la huella de Bogotá corresponde aproximadamente a 105 veces su tamaño y cubriría 16,3\% del territorio nacional.

En tercer lugar, según un estudio más reciente (León, 2013) se identifica una Huella Ecológica Local de 0,58 hectáreas locales per capita. Ante la significativa diferencia entre este indicador y los dos anteriores $(3,01$ y 2,85$)$, es relevante explicar brevemente la razón subyacente a esta disparidad. Este trabajo se aleja de las metodologías estandarizadas para el cálculo de la huella ecológica, las cuales favorecen su comparabilidad para las clasificaciones internacionales. En gran medida, la comparabilidad se logra por medio del uso de indicadores nacionales o globales adaptados a los ámbitos locales. Sin embargo, esta metodología ha sido criticada al menos

Leonardo Garavito G., Amparo De Urbina G. 
en dos aspectos (León, 2013): primero, la dificultad de asignar a una misma superficie diversos usos o recursos; y segundo, una alta probabilidad de doble o triple contabilidad asociada con el uso indiscriminado de información de escala nacional y global extrapolados para la escala regional o local.

En contraste, la metodología de la huella ecológica local busca ofrecer unos resultados de mayor utilidad y precisión para la toma de decisiones y la planificación urbana local. Por lo tanto, esta investigación enfrenta las críticas planteadas anteriormente con la finalidad de reducir su margen de error. En este sentido, la autora resalta que la particularidad del indicador de la Huella Ecológica Local consiste en el establecimiento de factores específicos de productividad para Bogotá y, por lo tanto, en la minimización o no utilización de los factores nacionales o globales.

Si bien, explicar en detalle las variaciones metodológicas de este indicador escapa al alcance de este texto, es relevante ofrecer un ejemplo de sus resultados en comparando con el cálculo estandarizado de la huella ecológica en un lugar diferente a Bogotá. Según León (2013), la huella ecológica local para la Región Metropolitana de Santiago en 2002 es de 1,2 hectáreas per capita; en contraste, la huella ecológica estandarizada según factores globales asciende hasta 3,6. Por lo tanto, según el cálculo de factores locales se podría esperar una reducción aproximada a la tercera parte de la huella ecológica estandarizada.

En el caso de Bogotá, con una huella ecológica local de 0,58 hectáreas por perso-
Figura 2. Representación de tres cálculos sobre la huella ecológica de Bogotá

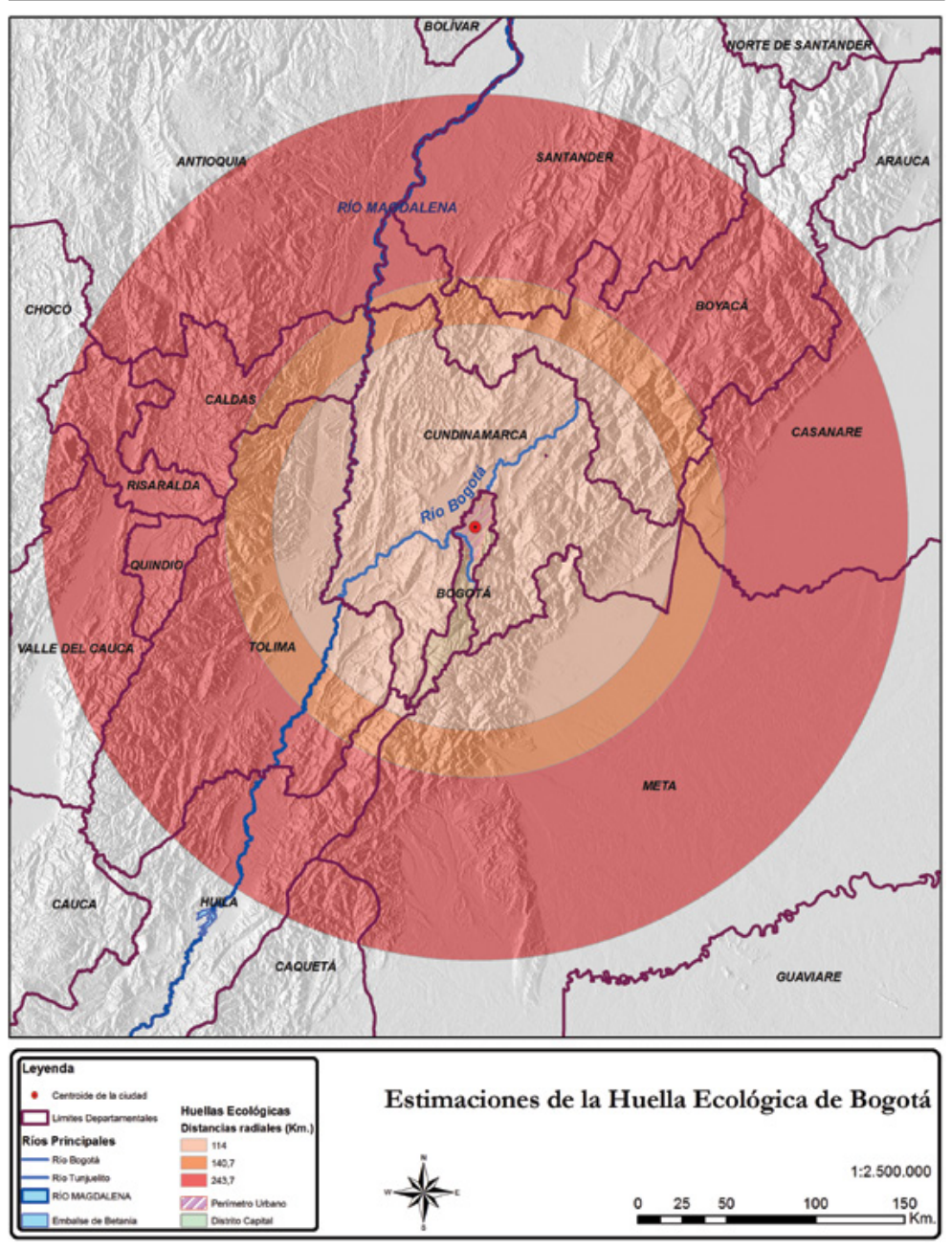

Fuente: elaboración propia.

na y con una población total de 7155052 personas (DANE, 2017) en 2008, la huella ecológica de la ciudad alcanza las 4149930 hectáreas, equivalentes a $41499 \mathrm{~km}^{2}$. Según lo anterior, el área total de la huella 
ecológica supera aproximadamente en 23 veces el tamaño de la ciudad y representaría $3,6 \%$ del territorio continental nacional. En la figura 2 corresponde al área sombreada en color crema.

En comparación con el caso de la Región Metropolitana de Santiago, la diferencia en el cálculo de la huella ecológica local de Bogotá es mucho más acentuada. En efecto, la huella estandarizada del Distrito Capital, a comienzos de la década del 2000, es aproximadamente cinco veces menor a la huella local para finales de esta misma década. Esta significativa variación implica una dificultad seria para concluir al respecto de la dimensión de la huella ecológica de la ciudad y, en este sentido, evidencia la necesidad de profundizar la investigación al respecto, con el fin de contar con más mediciones y llegar a unas conclusiones menos inciertas. A manera de hipótesis de partida para las futuras indagaciones, se plantea que la huella ecológica de Bogotá podría alcanzar entre 23 y 35 veces su área total (teniendo en cuenta los avances metodológicos para ajustar su cálculo con una perspectiva local), equivalente a una proporción del territorio nacional continental entre 3,6\% y 5,6\%. El estimado de 35 veces como cálculo aproximado superior corresponde con el cálculo de la tercera parte de la huella estandarizada, según su mayor valor entre la literatura revisada en los párrafos anteriores $(3,01$ hectáreas por habitante en 2002). En la figura 2, corresponde al área intermedia entre el rojo y el crema, sombreada en color naranja.

\section{territarias 40}

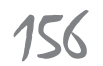

De forma adicional, se identifica otro trabajo enfocado en un aspecto particular de la huella ecológica: la huella ecológica alimentaria de Bogotá (Rodríguez, 2005). Lo interesante de este estudio radica en su esfuerzo por identificar los territorios específicos a escala nacional sobre los cuales se extiende o "pisa" dicha huella. De tal forma, es posible transitar de una estimación puramente abstracta, como las anteriores, hacia una visión más específica y localizada de los territorios impactados por la ciudad en función de su demanda alimentaria.

En primer lugar, según Rodríguez (2005), la huella ecológica alimentaria para Bogotá en 2002 es de 1952505 hectáreas, equivalentes a $1953 \mathrm{~km}^{2}$, aproximadamente. Esta estimación se refiere a la superficie de tierra que ocupa la ciudad para asegurar su supervivencia alimentaria en relación con el mercado interno nacional. De acuerdo con este indicador, la huella alimentaria total corresponde a cerca de $0,2 \%$ de la superficie continental nacional. No obstante, el autor plantea la necesidad de mayor investigación en este campo dada las limitaciones y deficiencias de la información oficial sobre consumo alimentario en la ciudad, lo que impide un cálculo más preciso. En este sentido, resalta que futuras indagaciones de este tipo podrían tener en cuenta también las cantidades de agua utilizadas en la producción agrícola para las ciudades.

En relación con la localización de la huella alimentaria, Rodríguez (2005) identifica el origen geográfico del $55 \%$ de los productos alimentarios que ingresan a

Leonardo Garavito G., Amparo De Urbina G. 
Bogotá por medio de la principal central mayorista de abastecimiento de la ciudad (Corabastos). En efecto, encuentra que el $51 \%$ del área de producción de alimentos para el Distrito Capital se concentra en el departamento de Cundinamarca, seguido de Boyacá $(8,5 \%)$, Valle $(8,3 \%)$, Tolima $(5,6 \%)$, Meta $(4,8 \%)$ y Huila $(4,2 \%)$, entre otros con menores participaciones.

A manera de conclusión, el estudio de Rodríguez (2005) brinda unas primeras claves para localizar la huella ecológica de Bogotá. Si bien, se enfoca solo la demanda alimentaria, sus resultados evidencian que se tiende a concentrar en los departamentos más cercanos a la ciudad, pero llega incluso hasta algunos de los municipios más periféricos del territorio nacional. Lo anterior, sumado al cálculo abstracto de la huella ecológica total (entre 23 y 35 veces el tamaño de la ciudad), permite plantear que los bordes de Bogotá en función de su huella ecológica superan ampliamente su perímetro urbano. A manera de ejercicio mental, si el área de la ciudad se extendiera hasta la totalidad de su huella ecológica, sus bordes no solo superarían al departamento de Cundinamarca, sino que incluso se extenderían hasta un siguiente anillo de departamentos circundantes.

\section{La ciudad urbanizada más allá del borde administrativo}

Este borde se refiere a la expansión urbana efectiva, como se dijo antes, responde a la transformación e integración de los territorios rurales y naturales a la mancha urbana de la ciudad. Para abordarlo, se presentan primero los factores físicos generales de la formación y ocupación de la ciudad. De manera complementaria, se plantea la construcción social de la frontera sur-norte como un elemento cultural con alto impacto en el desarrollo urbano de Bogotá. $Y$, para terminar, se enfoca en los factores detonantes de la urbanización al sur de la ciudad. Con lo anterior, se presenta un breve panorama que abraca desde la expansión urbana general de Bogotá durante el siglo Xx, representado en la figura 3 a continuación, hasta las particularidades del crecimiento urbano en su borde sur de la ciudad.

\subsection{Factores físicos para la ocupación y la forma de la ciudad}

Más que el proceso de urbanización en Bogotá, se busca comprender las razones que determinan la forma de la ciudad. Por este camino, el agua emerge como un elemento clave que moldea su perfil. $\mathrm{Al}$ respecto, siguiendo a Fabio Zambrano (comunicación personal, 2015), se abordan tres elementos para definir la estructura urbana de Bogotá: el escenario geográfico, el manejo del agua y la humedad.

Para comenzar con el escenario geográfico, las condiciones topográficas son esenciales. Hacia el oriente el territorio de Bogotá es abrupto, montañoso, de difícil poblamiento, acceso y, en general, la ciudad no tiende crecer en ese sentido. Sin embargo, el borde oriental representa el soporte ecológico de la ciudad por su oferta territarias 40

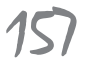


${ }^{3}$ Información registrada en Museo de Desarrollo Urbano (1998), Uribe Ramírez (1923), Direcciones Municipal y Departamental de Obras Públicas (1925), Sección de levantamiento, Secretaría de Obras Públicas Municipales (1932), Secretaría de Obras Públicas Municipales (1940), Plano de Bogotá (1950), Instituto Agustin Codazzi (1967), Mapa de la Sabana de Bogotá (1982), Alcaldía Mayor de Bogotá. Departamento Administrativo de Catastro Distrital (1989), Instituto de Crédito Territorial (1975). Para el borde sur: UPZ de las localidades Usme, Ciudad Bolivar, Bosa y Tunjuelito.

\section{territarias 40} 158

Figura 3. Proceso de urbanización en Bogotá durante el siglo xx

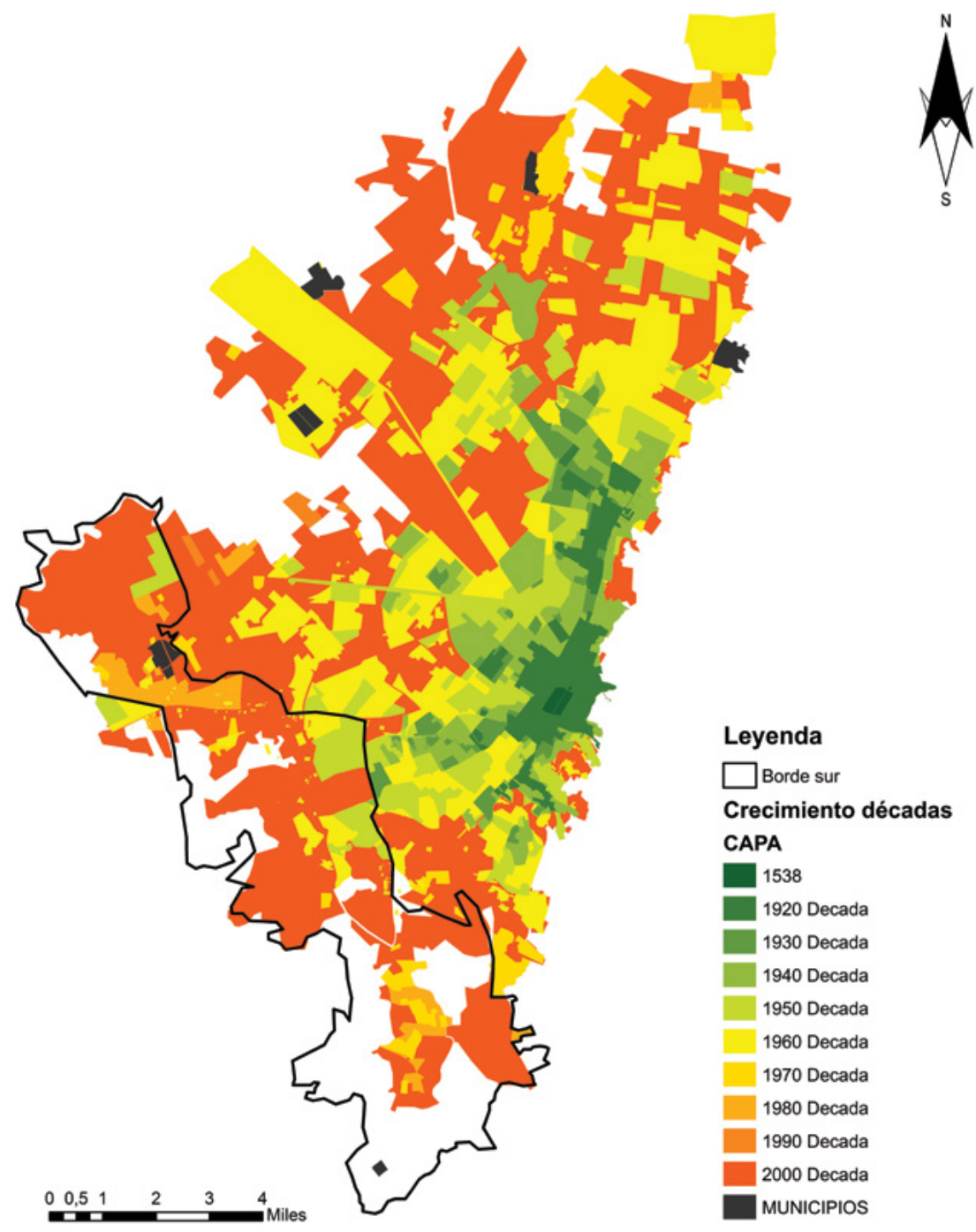

Fuente: elaboración propia con base en diversas fuentes cartográficas. ${ }^{3}$

ambiental, son los Cerros Orientales. Los pueblos indígenas de la región han tenido una relación cosmogónica muy fuerte con ese territorio, allí van a adorar a sus dioses en las lagunas y los cuerpos de agua sagrados. Desde la colonia, y hasta la actualidad, ha sido resignificado con lugares religiosos católicos como Monserrate, Guadalupe, La 
Peña, Egipto, etc. En otra dirección, hacia el noroccidente (altiplano cundiboyacense) es un territorio productor de alimentos especialmente de papa, fundamental para el sostenimiento de la ciudad. Históricamente, esta zona cuenta con asentamientos Muiscas con un vínculo continuo que se extiende hasta la ciudad de Tunja y el departamento de Boyacá, en general. En esta dirección, la ciudad se expande de forma constante. Con un giro más, hacia el sur de la ciudad, se encuentra un territorio de conquista tardía, marginal en su producción de alimentos y, por lo tanto, poco poblada. El gobierno distrital habita este borde hasta finales del siglo XIX, gracias al auge de la economía cafetera y el vínculo con municipios productores de café como Fusagasugá, Viotá y Sasaima.

Para el segundo elemento, el manejo del agua, es importante observar que la Sabana de Bogotá no es plana. La ciudad crece sobre un territorio en forma de batea, donde la parte más alta son los Cerros Orientales y la más baja es la rivera inundable del río Bogotá al occidente. Entonces, al occidente es el territorio de los humedales, amplias zonas de aguas estacionales, las cuales dificultaban la movilidad en épocas de la Colonia, en el eje que conecta a Bogotá con Honda, el río Magdalena, Cartagena y, finalmente, España y el resto del mundo. Esto lleva a la construcción de puentes y camellones para garantizar un tránsito continuo. En efecto, esto es lo que actualmente se encuentra desde el centro de la ciudad hasta su borde occidental en Fontibón. De forma complementaria, la parte más alta de la ciudad colinda con los Cerros y es lo primero que se urbaniza en la medida que se va secando la sabana y controlando el agua. Este proceso de secado se da por dos factores: por una parte, una acción natural derivada de un proceso milenario de drenado de zonas altas hacia las bajas. Por otra parte, la acción humana: es decir, los canales que se construyeron para secar más rápidamente y así, urbanizar. Esto empieza a hacerse desde mediados del siglo Xx y sigue hasta la actualidad.

El tercer elemento: la humedad, presenta una distribución muy diferenciada en el territorio de la Sabana, lo cual influencia de manera importante el proceso de urbanización. El sur de Bogotá es más seco y, como ya se dijo, de urbanización tardía en contraste con el norte, cuyas condiciones favorecían un estilo norteamericano y europeo, muy atractivo para las élites, con arborización, jardín y prado (Zambrano, comunicación personal, 2015). En efecto, la expansión urbana hacia el norte de la ciudad aún continúa. En suma, las condiciones topográficas, el manejo del agua y la humedad determinan en gran medida que la expansión urbana se concentré históricamente en el borde noroccidental y de manera más reciente hacia el sur, lo que genera una ciudad con una forma alargada de norte a sur, paralela a los Cerros Orientales y limitada parcialmente hacia el occidente por el río Bogotá y los humedales de la Sabana. En pocas palabras, el agua es un elemento determinante para la forma y la dinámica expansiva propias de esta ciudad. territarias 40

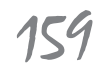

El borde no es como lo pintan. El caso del borde sur de Bogotá, D. C. 


\subsection{La construcción social del espacio: fronteras norte-sur}

El proceso de urbanización en Bogotá está fuertemente influenciado por una construcción social específica del espacio. Es decir, desde el Estado español y el Estado Republicano se construye el sur como receptor de lo que no se quiere en el norte, valorizando el norte a costa de desvalorizar el sur, en un proceso que ya se cuenta en siglos. En este asunto se identifican algunos factores que han definido y consolidado una barrera social entre el norte y el sur de Bogotá (Zambrano, comunicación personal, 2015), tales como: una frontera étnica, unos ejes de transporte exclusivos y un acceso excluyente al agua tratada.

En primer lugar, la frontera étnica entre el norte y el sur comienza desde finales del siglo XviII y se extiende en gran mediad hasta la actualidad. En un principio, al sur va la población indígena, luego serán también los obreros y, en general, los pobres; mientras hacia el norte se asienta la élite blanca en haciendas donde pueden recrear una vida con estilo europeo. Esto construye un imaginario cultural muy fuerte: donde hay población indígena no se valora, lo que es una paradoja, pues es de donde sale la gran parte de la comida para sostener la población urbana (Zambrano, comunicación personal, 2015).

En segundo lugar, la construcción de los ejes de transporte acentúa dicha frontera social conectando de forma preferencial el centro y el norte de Bogotá, valorizando el precio de la tierra y estimulando un proceso de urbanización en este eje. Así, a finales del siglo XVIII se empieza a construir el camellón del norte, fundamental para el ferrocarril y, posteriormente, la autopista norte y la avenida Caracas. De igual forma, hacia el norte se construye la primera carretera de Colombia, la Carretera Central del Norte que resulta de empedrar el camino real que va a Tunja, la actual Carrera Séptima.

En tercer lugar, en relación con el acceso al agua, el norte de la ciudad se beneficia de manera privilegiada de los primeros acueductos modernos de Bogotá. $\mathrm{Al}$ respecto, en 1938 se inauguran tres obras claves: la Represa de La Regadera, el tubo que trae el agua de La Regadera y la planta de tratamiento de Vitelma. A pesar de que La Regadera queda en el extremo sur de la ciudad en la localidad de Usme y la planta de Vitelma se ubica al suroriente, barrio San Cristóbal, sus aguas tratadas se ofrecen al norte de la ciudad (calle 72 , Chapinero Norte). Es llamativo y simbólico que barrios como San Cristóbal y las Cruces, vecinos de la planta de tratamiento, van a recibir el servicio de aguas tratadas entre cinco y ocho años más tarde. Así las cosas, además de los factores físicos, hay que agregar una construcción social de gran impacto sobre el desarrollo de la ciudad. Un imaginario que vincula el norte y el sur de Bogotá con un denso contenido simbólico (los blancos y los indios, los ricos y pobres, los territorios valiosos y los carentes de valor) que se traduce en proyectos urbanos altamente diferenciados $\mathrm{y}$ excluyentes, como es el caso del origen de

Leonardo Garavito G., Amparo De Urbina G. 
las principales vías de trasporte y el acceso a servicio de aguas tratadas.

\subsection{Procesos detonantes de la urbanización hacia el sur}

A partir de lo anterior, si bien, la urbanización hacia el sur de Bogotá no es tan dinámica como al norte, es pertinente especificar al menos tres de sus procesos detonantes. En primer lugar, la erradicación del Paseo Bolívar a comienzos del siglo xx, ubicado en el centro de la ciudad y habitado por una población humilde en condiciones extremas, consolida el proceso de construcción de habitaciones para los obreros hacia el sur (Colón, 2005). La epidemia de gripa de 1918 que afecta ampliamente a la población más vulnerable, como la del Paseo Bolívar, genera un impulso excluyente de desplazarla fuera del corazón de la ciudad. Hacia el norte, en Chapinero, se desarrolla un tipo de urbanización distinta (Zambrano, comunicación personal, 2015), entonces esta expansión urbana se dirige hacia el sur. Así, también construyen hospitales (La Misericordia ${ }^{4}$, San Juan de Dios de la Hortúa ${ }^{5}$, Sibaté S $^{6}$ San $\mathrm{Carlos}^{7}$ ), progresivamente más lejanos del área urbana consolidada. La creencia en que las enfermedades se transmitían por el aire y el miedo al contagio se tradujo en hospitales cada vez más distantes del centro.

El segundo proceso es el desarrollo de elementos de infraestructura urbana desde la década de 1940. Por ejemplo, la prolongación de la Avenida Caracas hacia el sur estimula la aparición de barrios en ambos costados de la vía (San Carlos, Tunjuelito, Abraham Lincoln, entre otros). Este camino conecta hasta Usme y se vincula con el proyecto de la represa de La Regadera. Así mismo, en las cercanías del tubo que lleva el agua de La Regadera a la planta de Vitelma también se generan nuevos asentamientos. Debido a la falta de acueducto en el sur, la población lo perfora y empieza a sacar agua de este. Finalmente, la construcción de la Escuela de Policía General Santander (1938) brinda un impulso adicional al proceso de urbanización hacia el sur de Bogotá.

El tercer proceso es el desarrollo de las actividades económicas tradicionales del borde sur, como la extracción de recursos naturales ( Zambrano, comunicación personal, 2015). Por una parte, para la segunda mitad del siglo xx la extracción de barro se desplaza desde el borde oriental hacia el borde sur, a lo largo de la rivera del rio Tunjuelito. Esta explotación es clave para la urbanización de las localidades de Tunjuelito, Rafael Uribe y San Cristóbal, donde también se cocina la cerámica. Progresivamente, los frentes mineros se extienden también en la Localidad de Ciudad Bolívar. Por otra parte, en las localidades de Bosa y el municipio de Soacha se destaca una zona de producción agrícola vinculada con el río Bogotá y el eje de humedad del borde occidental, incluyendo a las localidades de Suba, Engativá y Fontibón.

En resumen, la expansión urbana del sur de Bogotá es un proceso tardío pero dinámico, cargado de una impactante carga
${ }^{4}$ La fundación del Hospital de la Misericordia para Niños Pobres fue en 1897 en memoria de María Josefa Cualla, esposa de José Ignacio Barberi, médico pediatra y abogado quien bizo posible la creación del Hospital (Gutierrez Cely, 2007).

${ }^{5}$ Fundado en 1564 en un predio ubicado al oriente de la Catedral Primada, $y$ administrado durante La Colonia por los monjes de San Juan de Dios — quienes le dieron su nombre-, fue trasladado en 1739 bacia la manzana ubicada entre las calles 11 y 12 y carreras 9 y 10. A partir de 1926 funcionó en su ubicación actual, en la finca denominada Molino Tres Esquinas o de la Hortúa (Corporación La Candelaria, 2006).

${ }^{6}$ El Hospital Neuropsiquiatrico de Sibaté, financiado desde el Estado, por medio de la Beneficencia de Cundinamarca, recibiósus primeros pacientes en 1937, lo que dio inicio oficial a un proyecto que tenía 15 años. Fue en 1921 cuando se firmó un acta que autorizaba la realización de planos del nuevo manicomio. En estas instalaciones se continuaría con la atención que se daba en el Asilo de Locos, creado en Bogotá en 1873, ubicadas en la calle

territarias 40

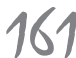


$\Leftarrow$

5 con Avenida Caracas, en la bacienda conocida como Ningunaparte (Simpson Beltrán, 2015).

${ }^{7}$ Fundado en 1948, en tierras de la hacienda conocida como del Llano de la Mesa, financiado por Gustavo Restrepo Mejía, un acaudalado hombre de negocios, que dejó estipulado en su testamento la construcción de este hospital, destinado a tuberculosos (Corporación La Candelaria, 2006).

\section{territarias 40} 162 simbólica cargada de discriminación. Es tardío en función de los factores físicos del territorio que facilitan una primera urbanización hacia el norte de la ciudad, reforzada con las primeras inversiones públicas en infraestructura urbana. Hasta inicios del xx la expansión urbana del sur se dinamiza con la construcción de barrios obreros, hospitales e infraestructura, y el desarrollo de actividades extractivas y agrícolas en su borde. Todo esto, en el marco de una frontera social centenaria que tiende estigmatizar al territorio sur y a sus habitantes.

\section{El borde del conflicto socio-territorial}

En esta sección se presenta una mirada al borde sur de Bogotá desde la perspectiva de la movilización social y de los procesos participativos que problematizan los efectos negativos de la expansión urbana por medio de variadas causas y consecuencias. Este borde señala un territorio más subjetivo que los anteriores, en donde cotidianamente está en disputa la sobrevivencia de sus habitantes, su apropiación del territorio y sus valores culturales, sociales y ambientales en relación con su identidad territorial.

El borde sur de la ciudad se relaciona directamente con la cuenca urbana del río Tunjuelo, la cual se extiende sobre siete de sus localidades: Bosa, Kennedy, Tunjuelito, Rafael Uribe Uribe, San Cristóbal, Usme y Ciudad Bolívar. Como se verá más adelante, los antecedentes, las problemáticas y propuestas de los principales actores y procesos sociales movilizados en el borde sur de la ciudad se encuentran vinculados de diversas maneras con este territorio.

De acuerdo con Torres Ruíz (2015), es posible identificar una serie de procesos que caracterizan la incorporación de la cuenca del Tunjuelo al espacio urbano de Bogotá, entre estos se destacan: primero, desde finales del siglo XIX y del XX las autoridades locales y nacionales comienza a reconocer la importancia de esta cuenca para el abastecimiento de agua de la ciudad. Segundo, a partir de las décadas de 1950 y 1960, en el marco de una explosión urbana a escala nacional y local, inicia un proceso de urbanización irregular de la cuenca que se extiende hasta la acutalidad. Dicho proceso será estimulado por las utoridades por medio de la construcción de vías de transporte que facilitan la salida y el acceso por el sur de la ciudad y, además, de los embalses que liberan progresivamente tierras inundables y semi-inundables para ser integradas al suelo urbano. Tercero, hacia el decenio de 1980 se consolida el asentamiento de industrias en los márgenes de la cuenca del Tunjuelo con un alto impacto ambiental, en un contexto de ausencia de regulación y control por parte de las autoridades. Las dos actividades industriales más controversiales corresponden con las curtiembres y la minería extractiva. Por ultimo, en 1987 se estable el relleno sanitario de Doña Juana en el costado occidental de la cuenca baja del río Tunjuelo (localidad de Ciudad Bolívar) el cual, desde entonces, recibe las basuras de la ciudad. 
La agregación e interacción de los anteriores procesos deviene en una serie de tragedias sociales y ecológicas que, durante los últimos años de siglo Xx y los primeros del siglo XXI, generán un contexto social y político propicio para la consolidación de múltiples movilizaciones y procesos sociales en defensa del borde sur. Para comenzar, en 1997 se colapsa el relleno sanitario de Doña Juana, lo que genera un deslizamiento de 800 mil toneladas de basura sobre dos montañas de la localidad de Usme (El Tiempo, 1997); en 2002, el río Tunjuelo multiplica en 150 veces el volumen de su caudal, desbordando los sistemas de contención en Usme, inundando zonas de explotación minera, damnificando a tres mil personas, y cubriendo totalmente de agua 600 casas en 22 manzanas (Gutiérrez Roa, 2008); y, finalmente, en 2009 ocurre un deslizamiento de dos millones de metros cúbicos de tierra, asociado con la explotación minera, sobre 90 casas del barrio Villa Jackie (Torres Ruiz, 2015b).

Los anteriores hechos permiten señalar que el origen y la evolución de las movilizaciones que problematizan el territorio del borde sur de la ciudad se caracteriza por al menos, dos elementos claves (Secretaría Distrital de Ambiente, 2009). Por una parte, dadas unas condiciones territoriales de múltiples conflictos sociales y ecológicos, surge una gran cantidad de actores. Estos actores varían desde unos enfocados en alguna de las problemáticas específicas, hasta procesos organizativos de mayor escala que buscan aglutinar a diversas organizaciones y líderes, inclu- yendo no solo a iniciativas urbanas sino también a los actores rurales del borde sur. Por otra parte, en cuanto al desarrollo de su identidad colectiva, la gran mayoría de los actores se encuentran vinculados, directa o indirectamente, con un proceso denominado 'ecologismo popular'. Como su nombre lo indica, esta perspectiva busca generar estrategias integrales a partir del conocimiento científico en combinación con el conocimiento popular.

A manera de ejemplo, dos de los principales procesos sociales que impulsan la movilización y la participación en el borde sur de Bogotá, que buscan agrupar diferentes organizaciones y líderes locales son Asamblea Sur y Territorio Sur. Estos procesos comparten un origen más o menos común que se remonta a los años 1997 y 1998. En aquel momento surge un escenario llamado la Mesa Interlocal, en esta se propone la iniciativa de replantear el territorio del río Tunjuelo desde el concepto unificador de cuenca hidrográfica $y$, por lo tanto, el reconocimiento de una complejidad territorial que trasciende la particularidad de cada localidad (Torres Carrillo, 2015a). Por lo tanto, la Mesa Interlocal configura un lugar de encuentro entre los líderes de las distintas localidades del sur de Bogotá, en el cual se desarrolla un marco conceptual común sobre las políticas públicas, la productividad territorial, la apropiación y la construcción del territorio, y el fortalecimiento organizacional comunitario (Zárate et al., 2013). De forma complementaria, las tragedias expuestas anteriormente estimulan el despliegue de territarias 40

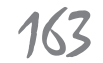


un amplio repertorio de acciones colectivas que abarcan desde las protestas y las manifestaciones, hasta la interposición de recursos legales, la presencia en espacios formales de participación ciudadana, a la par de acciones culturales y simbólicas.

A pesar de los vínculos de nacimiento entre Asamblea Sur y Territorio Sur, en el 2002 y ante la inundación del Tunjuelo, las "divergencias en discurso y método llevaron a enfrentamientos de poder que terminaron en la fragmentación del proceso inicial" Procesos Participativos en la Cuenca Río Tunjuelo, 2008) (Garcia, \& Ramírez, 2010). No obstante, según una serie de entrevistas con activistas de Asamblea Sur (Reyes, comunicación personal, Agosto 18, 2016; Villareal, comunicación personal, Septiembre 7, 2016), y en consonancia con el diagnóstico social del POMCA del Tunjuelo (Secretaría Distrital de Ambiente, 2009), la presencia de múltiples actores se asume como algo que "fortalece y enriquece, al permitir la expresión del múltiple sentir de la comunidad" (p. 337), en vez de ser visto como un factor de competencia. Según la página electrónica Procesos Participativos en la Cuenca Rio Tunjuelo (2008) vinculada con el proceso de Territorio Sur, su diferencia central con Asamblea Sur, es que el primero se enfoca más en la formación de niños y jóvenes en el tema ambiental, orientándolos hacia procesos participativos locales, mientras que la seguna se concentra en el trabajo comunal y político con diversos líderes de la cuenca.
De acuerdo con diversas fuentes (Reyes, comunicación personal, Agosto 18, 2016; Torres Carrillo, 2015; Torres Ruiz, 2015; Hernández, Flores \& Naranjo, 2011; Secretaría Distrital de Ambiente, 2009), las problemáticas sociales y ambientales más relevantes y persistentes, que configuran ese borde sur del conflicto social en Bogotá, incluyen: primero, la situacion de riesgo, hacinamiento y miseria de múltiples poblaciones habitantes de la ronda del río Tunjuelo. Segundo, la explotación minera legal e ilegal vinculada con la contaminación del aire, los cuerpos de agua, el deteriorio ecosistémico y un mayor riesgo de inundaciones en la región. Tercero, los problemas de gestión del relleno sanitario de Doña Juana en relación con la disposición de basuras, el manejo de los lixiviados, así como la lucha por su no expansión, en respuesta a los problemas de contaminación para los cuerpos de agua circundantes y un permanente riesgo para la salud de sus habitantes vecinos. Y cuarto, una serie de conflictos asociados con la expansión urbana (legal e ilegal) en los cuales se observa una debil presencia institucional, asociada con tensiones entre los diversos niveles de gobierno (local, regional y nacional), y con una planificación, ordenamiento y gestión territorial pobre e irresponsable. De forma complementaria, se reconoce una amenaza constante y creciente a la cultura y los modos de vida e identidad campesina, de gran relevancia en la localidad de Usme (cuyo suelo rural y de expansión urbana representa más de $70 \%$ de su suelo total), así como una

Leonardo Garavito G., Amparo De Urbina G. 
amenaza ecológica sobre los territorios de alto valor ecológico como los páramos y humedales de la región.

En suma, este borde sur del conflicto y la movilización social expresa un relevante mensaje político, social, ecológico y cultural acerca de los retos y las limitaciones que enfrentan las ciudades general, y Bogotá en particular, para asegurar un funcionamiento aceptable, dando visibilidad a la gran inequidad e injusticia social, económica y ecológica que caracteriza a esta periferia urbana. En este sentido, la evolución de la acción colectica y la movilización social en el sur de la ciudad ha demostrado su valía tanto en la lucha por por la satisfacción de sus necesidades básicas, la búsqueda de unas condiciones de vida dignas para su población, la defensa de los ecosistemas estratégicos relacionados con el agua, como en la construcción de una identidad cultural y territorial y la busqueda de un papel protagónico en la planificación y el gobierno local. En efecto, según Torres Carrillo (2015) uno de los principales logros liderados por Asmablea Sur es la construcción de una "perspectiva territorial y estructural de su comprensión de los problemás ambientales y sociales" (p. 116), la cual representa un proceso de tránsito y aprendizaje desde un foco ambiental y local hacia una mirada integral del territorio. Sin duda, el sustento físico y espacial de estos procesos, correspondiente con la cuencua del río Tunjuelo, es un motivante y un elemento central en la construcción de su identidad y sus propuestas. No obstante, los retos planteados no son problemas exclusivos del borde sur sino, más bien, son desafíos vinculados con el modelo de desarrollo urbano de toda la ciudad, que pueden llegar a afectarla en su totalidad. Al respecto nada más ilustrativo que el la gran dependencia y riesgo de contar con un solo relleno sanitario con múltiples debilidades en su gestión, como es el caso de Doña Juana.

\section{Conclusiones}

Para comenzar, se resaltan los aportes que ofrece este artículo al proyecto de investigación que le da origen. En primer lugar, ayuda a evidenciar y analizar la dimensión de la problemática del agua para Bogotá. En efecto, desde su fundación, el agua influencia su lugar de origen. De manera posterior, el manejo del agua y la humedad determinan, en gran medida, sus patrones de expansión territorial en dirección al norte y al occidente, así como su forma alargada y paralela a los Cerros Orientales. De forma más contemporánea, el acceso excluyente al agua tratada hace parte de los factores que configuran una frontera social que privilegia a los habitantes del norte de la ciudad sobre los del sur. Hecho clave que determina la presencia y relevancia de los acueductos comunitarios en las periferias de la ciudad. En cuanto al sur de la ciudad, en específico, el agua del río Tunjuelo emerge como un recurso clave para sostener el abastecimiento de la ciudad y la explosión urbana del siglo XX. Asimismo, desde principios XXI la cuenca del río Tunjuelo se consolida como un 
símbolo social y cultural de la lucha y la defensa del territorio, de la identidad y la vida campesina en la Bogotá rural e incluso, como un llamado al reconocimiento de su carácter sagrado tal como lo fue para los habitantes originarios de estos territorios.

En segundo lugar, en cuanto a las redes de práctica y aprendizaje, la apropiación del conocimiento y la gestión colaborativa, este artículo tiene una doble intención. Por una parte, contextualizar, dimensionar y dar una mayor visibilidad al esfuerzo y compromiso de los acueductos comunitarios y de los procesos sociales que defienden el agua y el territorio en el borde sur de Distrito Capital. Por otra parte, ofrecer insumos de información y análisis para la comprensión, la reflexión y la acción creativa en cuanto a la complejidad del borde sur de Bogotá, lo cual puede ser relevante también para otras ciudades que comparten unas condiciones más o menos similares, especialmente, en Colombia y América Latina.

$\mathrm{Al}$ abordar el caso del borde sur de Bogotá es inevitable comenzar por reconocer las dinámicas generales vinculadas con la forma y la ocupación del territorio que sostiene a la ciudad en su totalidad. En este sentido, es relevante comenzar por la evolución de su delimitación política y administrativa, la cual se expande a gran velocidad a lo largo del siglo $\mathrm{xx}$, tratando de responder a un acelerado crecimiento poblacional, al interés político e institucional creciente de gobernar y ejercer control sobre el territorio urbano, cuestionados por procesos de expansión urbana espontáneos e ilegales que lo cuestionan y retan constantemente.

De forma complementaria, más allá de los perímetros legales, la dinámica de la expansión urbana concreta de la ciudad también se vincula con las particularidades específicas del borde sur. En efecto, la urbanización tardía del sur de Bogotá se relaciona inicialmente con las características biofísicas del territorio. No obstante, durante el siglo XX esta tendencia es reforzada por la reafirmación de una frontera social simbólica heredad desde la colonia, que estigmatiza su territorio y a sus habitantes, complementada con una gestión gubernamental que prioriza la inversión pública en infraestructura urbana del centro hacia el norte de la ciudad.

En consecuencia, hacia finales del siglo xx y comienzos del XXI, no es extraño que se configure un borde sur contestatario, lleno de acción colectiva y movilización social que reivindica los vínculos entre la cultura y la naturaleza, que apropian el territorio y defienden las identidades territoriales ancestrales, las tradicionales o inclusos emergentes, que reclaman el derecho a la vida digna en la ciudad y denuncian múltiples injusticias, carencias y deudas sociales y ecológicas. Estos procesos sociales retan el establecimiento y evidencian sus debilidades, enfrentan a los poderes económicos, la inercia del crecimiento urbano y, en suma, critican el paradigma capitalista dominante en defensa de la naturaleza, del agua, de la diversidad de su población y, por lo tanto, del derecho a la ciudad.

Leonardo Garavito G., Amparo De Urbina G. 
En un movimiento recíproco y complementario desde la naturaleza hacia la cultura, es de resaltar el rol del espacio geográfico y del agua en relación con esta movilización social en el caso del Bogotá: primero, el río Tunjuelo en sí mismo y, después, la visión de pensar en su cuenca hidrográfica como un territorio integrador y generador de identidades colectivas. Esta dinámica cuestiona la utilidad y pertinencia de los límites político-administrativos al interior de la ciudad (las localidades), del perímetro urbano de la ciudad con el entorno que lo rodea, entre lo urbano y lo rural en incluso, conecta el presente y el pasado reciente de la ciudad con un pasado y una identidad ancestral. Así las cosas, el valor simbólico de este tipo de movilizaciones trasciende su efectividad política, planteando la necesidad de juzgarla más por la pertinencia y la urgencia de su mensaje para el devenir de las ciudades y los territorios que habitan.

En relación con la imposibilidad de disolver los vínculos entre la ciudad y la naturaleza la reflexión sobre la huella ecológica de Bogotá es contundente: la ciudad depende de un entorno mucho mayor a su propio territorio (entre 23 y 35 veces aproximadamente en el caso de Bogotá) para garantizar su sustento. En este sentido, el impacto y alcance del Distrito Capital se extiende de manera implacable sobre sus territorios vecinos y alcanza en distintas medidas todo el territorio nacional. Entonces, el borde del área requerida para la sostenibilidad de la ciudad señala una clara dependencia de muchos otros territorios campesinos, rurales, de abastecimiento de agua y de otros recursos naturales. No obstante, la escasa investigación al respecto es una clara señal de un conocimiento académico e institucional insuficiente sobre este fenómeno, lo cual señala un bajo nivel de conciencia social y política al respecto.

Todo lo anterior indica un grado importante de desconexión entre la cultural y el territorio de ciudad y, por lo tanto, dirige la discusión hacia el papel de las movilizaciones y procesos sociales que (en un esfuerzo quijotesco) buscan dar visibilidad y ofrecer alternativas a las situaciones conflictivas derivadas de esta situación. En este sentido, es útil retomar a Magnaghi (2011) y su propuesta teórica acerca de la incapacidad de las metrópolis modernas para estimular la emancipación de sus habitantes, la imposibilidad de disolver los vínculos con el territorio y la naturaleza y, por lo tanto, la urgencia y relevancia del regreso al lugar y a la escala local. Es decir, el proceso de urbanización del siglo Xx en Bogotá y la constitución de su borde sur son ejemplos interesantes de la emergencia de problemáticas y retos que parecen rebasar la capacidad de las entidades encargadas del manejo de la ciudad. Ante este panorama, es urgente un llamado por niveles de reflexividad social y política crecientes, y esto se relaciona de forma inevitable con el desarrollo de la acción colectiva y las movilizaciones sociales en un territorio. En este sentido, el borde sur de la ciudad tendría mucho que aportar al desarrollo urbano de la ciudad de cara al siglo XXI. 


\section{Referencias}

Alcaldía Mayor de Bogotá. Departamento Admministrativo de Catastro Distrital. Unidad de Cartografía. (1989). Plano de barrios de Bogotá D.C. Última versión corregida. Recuperado de http:// mapwarper.net/maps/10492\#

Castilblanco, L. A. (2015). Importancia del perímetro urbano en las zonas de expansión: Caso Bogotá. XX Congreso Internacional del CLAD sobre la reforma del Estado y de la administración pública. Lima: Inédito.

Colón, L. C. (2005). El saneamiento del Paseo Bolívar y la vivienda obrera en Bogotá. Revista Urbanismos(2), 104-115.

Contraloría de Bogotá D.C. (2003). Informe anual sobre el estado de los recursos naturales y del medio ambiente. La huella ecológica de Bogotá, D.C. Cálculo y evaluación de su utilidad. Bogotá: Contraloría de Bogotá D.C.

Corporación La Candelaria (2006). Hospital de San Carlos. En A. Escobar WilsonWhite (Ed.), Atas Histórico de Bogotá. 1911-1948 (pp. 262-266). Bogotá: Editorial Planeta.

Corporación La Candelaria (2006). Hospital San Juan de Dios de la Hortúa. En A. Escobar Wilson-White (Ed.), Atlas histórico de Bogotá. 1911-1948 (pp. 267-274). Bogotá: Editorial Planeta.

Direcciones Municipal y Departamental de Obras Públicas (1925). Plano Bogotá Futuro. Recuperado de http://ma-

\section{territarias 40} pwarper.net/maps/8907\#
Escobar, A. (2005). Más allá del tercer mundo: globalización y diferencia. Bogotá: Instituto Colombiano de Antropología e Historia (ICANH).

García, D., \& Ramírez, S. (2010). Procesos Participativos en la Cuenca Rio Tunjuelo. Recuperado de https:// app.assembla.com/spaces/cdr/wiki/ Procesos_Participativos_en_la_Cuenca_Rio_Tunjuelo

Global Footprint Network (2017). Global Footprint Network. Recuperado de http://www.footprintnetwork.org/ en/index.php/GFN/page/world_ footprint/

Gutiérrez-Cely, E. (2007). Capítulo III. Vida cotidiana y cultura. En Gutiérrez E. (Comp.) Historia de Bogotá. Siglo XIX, Segunda edición (pp. 77-112). Bogotá: Villegas Editores.

Gutiérrez-Roa, É. (25 de agosto de 2008). Tunjuelito sigue inundado. El Espectador. Recuperado de https://www.elespectador.com/impreso/bogota/articuloimpreso-tunjuelito-sigue-inundado Hernández, A., Flores, J., \& Naranjo, M. (2011). Gobernanza ambiental, trayectoria insitucional y organizaciones sociales en Bogotá: 1991-2010. Madrid: Fundación Carolina.

Instituto de Crédito Territorial. Departamento de Estudios e Investigaciones (1975). Inventario de zonas subnormales de vivienda y proyectos ICT de desarrollo progresivo. Recuperado de http://mapwarper.net/maps/8903

Instituto Geográfico Agustin Codazzi (1967). Plano de la ciudad de Bogotá.

Leonardo Garavito G., Amparo De Urbina G. 
Recuperado de http://mapwarper.net/ maps/4786\#

Instituto Geográfico Agustín Codazzi (1982). Mapa de la Sabana de Bogotá. Recuperado de http://mapwarper.net/ maps/5103\#

León, S. (2013). Indicadores de tercera generación para cuantificar la sustentabilidad urbana. ¿Avances o estancamiento? EURE, 39(118), 173-198.

Magnaghi, A. (2011). El proyecto local. (R. Hincapié Aristizabal, Trad.) Documento de trabajo.

Mantilla, A. (1974). Zonificación: Normas en el siglo 20-Su relación con la estratificación urbana. Bogotá: Subdirección de Desarrollo Social, Departamento Administrativo de Planeación Distrital.

Martinez, S. M. (2007). Sintesis de la problemática de las áreas desarrolladas informalmente. Bogotá: Secretaría Distrital de Planeación, Dirección de Legalización y Mejoramiento Integral de Barrios.

Ministerio de Hacienda y Crédito PúblicoInstituto Geográfico Agustin Codazzi (1946). Plano Cundinamarca-Carta preliminar. Planchas 247-I-A. 246-IIA. 228-III-A. 246-II-B. 227-IV-B. 247 I-C. 246-II-C. 228-III-C. 246-II-D y 227-IV-D. Bogotá: MinHacienda-IGAC.

Museo de Desarrollo Urbano (1998). Bogotá D.C. Instante, memoria, espacio. Bogotá: Museo de Desarrollo Urbano.

Observatorio Ambiental de Bogotá (2017). Cobertura Residencial y Legal Servicio de Acueducto (CAC). Recuperado de http://oab.ambientebogota.gov. co/es/indicadores-reglamentados/ indicadores $? \mathrm{id}=53 \& \mathrm{v}=1$

Oficina del Plan Regulador de Bogotá (1951). Plan Piloto de la ciudad, Decreto 185 de 1951. Sistema vial de la ciudad Decreto 480 de 1951. Recuperado de http://mapwarper.net/maps/5118\#

Parrado, C. C. (2001). Metodología para la ordenación del territorio bajo el prisma de la sostenibilidad (estudio de su aplicación en la ciudad de Bogotá D.C.). Barcelona: Universitat Politecnica de Catalunya.

Pizano de Narvaez, E. (2005). Del UPAC a la UVR Vivienda en Colombia 19702005. Bogotá: Fundación Konrad Adenauer Stiftung.

Redacción El Tiempo. (13 de Noviembre de 1997). Protesta por Doña Juana. El Tiempo. Recuperado de: https://www. eltiempo.com/archivo/documento/ MAM-670005

Rincón, L. H. (2010). Proceso de Incorporación de la Zonificación al Planeamiento Urbano de Bogotá 1950-2000. Universidad Nacional de Colombia, Maestría en urbanismo. Bogotá: Sin publicar.

Rodríguez, B. (2005). Nuestro pan de cada día: huella ecológica alimentaria de Bogotá. En Anais do X Encontro de Geógrafos da America Latina (pp. 1278112803). São Paulo: Universidade de São Paulo.

Saldarriaga, A. (2000). Bogotá siglo XX: urbanismo, arquitectura y vida urbana. Bogotá: Editorial Escala.

Sección de levantamiento, Secretaría de Obras Públicas Municipales (1932). 
Plano de la Ciudad de Bogotá. Recuperado de http://mapwarper.net/ maps $/ 5390$

Secreataría de Obras Públicas. Departamento de Urbanizaciones y Demarcaciones (1938). Plano de la ciudad en Barrios. Recuperado de http://mapwarper.net/ maps/10619\# y http://mapwarper. net/maps/10620

Secretaría de Obras Públicas Municipales (mayo de 1940). Trazos sobre un plano de 1938. Plano División del área urbanizable de la ciudad en zonas de destino. Recuperado de http://mapwarper.net/ maps/8900\#

Secretaría Distrital de Ambiente (2009). Diagnóstico POMCA Tunjuelito. Bogotá: Secretaría Distrital de Ambiente.

Simpson-Beltrán, V. (2015). Psiquiatría, moralidad y locura. La construcción del Hospital Psiquiatrico de Sibaté y discurso psiquiatrico de 1916 a 1966. (Tesis de grado, Pontificia Universidad Javeriana, Bogotá, Colombia). Recuperado de https://repository.javeriana.edu.co:8443/bitstream/handle/10554/18666/SimpsonBeltranValentina2015.pdf?sequence $=1$

s.d. (1950). Plano de Bogotá. Recuperado de http://mapwarper.net/maps/4787

Torres-Carrillo, A. (2015a). El proceso histórico de Asamblea Sur. En A. Torres
Carrillo, \& A. Torres Ruíz, Acción colectiva, gestión territorial y gobernanza democrática en Bogotá (pp. 56-83). Bogotá: Universidad Piloto de Colombia. Torres-Ruiz, A. (2015b). Los conflictos ambientales en la cuenca del río Tunjuelo en Bogotá. En A. Torres Carrillo, \& A. Torres Ruiz, Acción colectiva, gestión terrtorial y gobernanza democrática en Bogotá (pp. 22-54). Bogotá: Universidad Piloto de Colombia.

Uribe-Ramírez, E. (1923). Plano Bogotá Futuro. Recuperado de http://mapwarper.net/maps/4771

Wackernagel, M., Onisto, L., Callejas, A., López Falfán, I., Méndez García, J., Suárez Guerrero, A., et al. (1997). Ecological Footprints of Nations: How Much Nature Do They Use? How Much Nature Do They Have? Toronto: Commissioned by the Earth Council for the Rio+5 Forum. Distributed by the International Council for Local Environmental Initiatives.

Zárate-Rueda, R., Fonnegra-Castro, B., \& Mantilla-Pinilla, E. (2013). Aproximaciones al quehacer de la Red Juvenil Territorio Sur: reconstrucción de una cultura ambiental desde un enfoque participativo. Prospectiva, 273-293. 